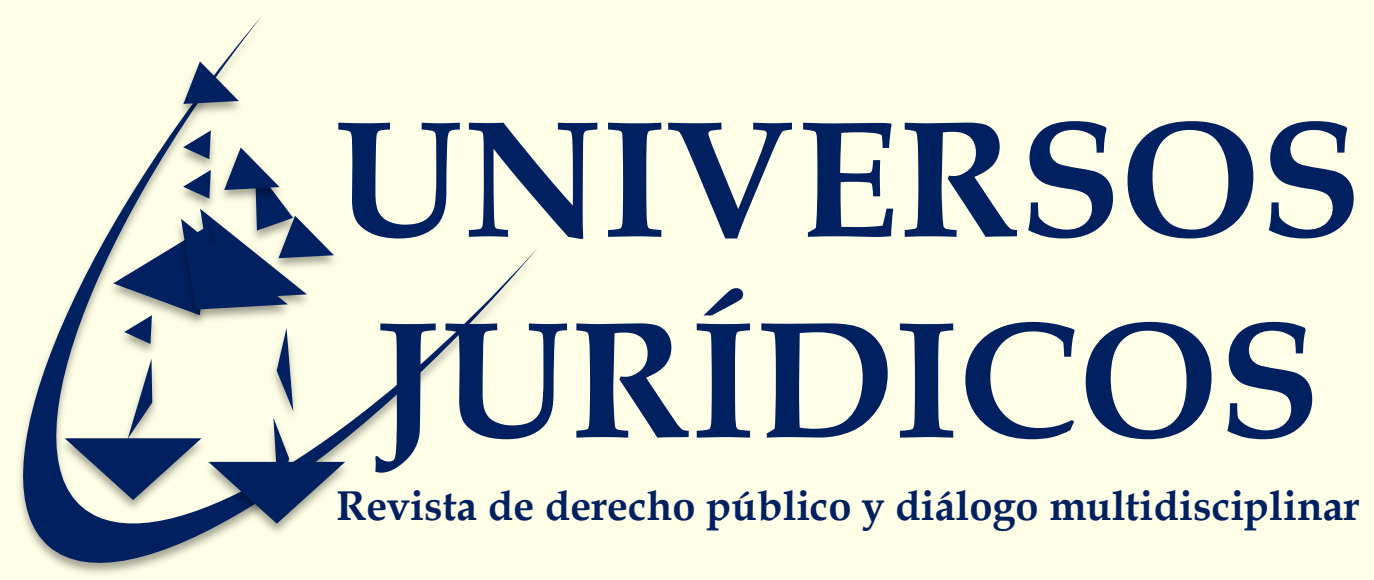

\title{
Los menores ante los peligros digitales en México y su protección legal
}

Concepción Regalado Rodríguez ${ }^{1}$

1. Profesora investigadora de Tiempo Completo de la Facultad de Derecho, Campus III, de la Universidad Autónoma de Chiapas. Doctora en Derechos Humanos, integrante del Cuerpo Académico en Derechos Humanos. Profesora en la Maestría y Doctorado en Administración Pública en el Instituto de Administración Pública de Chiapas, A.C. Líneas de Investigación y Generación del Conocimiento: Políticas Públicas, Energía. Género, Derechos Económicos y Sociales.

concepcion.regalado@hotmail.com

UNIVERSOS JURÍDICOS. Revista de derecho público y diálogo multidisciplinar. Año 8, No. 15, noviembre 2020-abril 2021, ISSN 2007-9125

Cómo citar este artículo en formato APA Regalado, C. (2020). Los menores ante los peligros digitales en México y su protección legal. Universos Jurídicos, 236-259.

Fecha de recepción: 13 de junio de 2020

Fecha de aceptación: 18 agosto de 2020 


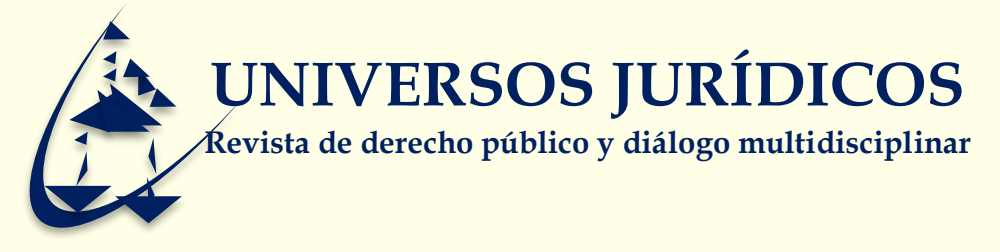

\section{Introducción}

En poco tiempo, la tecnología de la información ha evolucionado de una manera acelerada generando un sistema de vida diferente en la sociedad actual. En el área de informática, han surgido nuevos paradigmas y un dinamismo tal que, las innovaciones se vuelven obsoletas con una rapidez vertiginosa. Bajo este escenario, en los últimos años, niños y adolescentes han aprendido tempranamente el manejo de los equipos electrónicos; sin embargo, aunque han adquirido habilidades digitales, ignoran los peligros que su uso implica.

El uso de internet ha crecido en mayor medida, desplazando a la televisión, y con ello, su influencia, como medio de comunicación, hoy por hoy es mayor en niños y jóvenes en todo el mundo.

Desafortunadamente, ante esta dinámica del escenario global, son precisamente los menores quienes pueden sufrir de actos delictivos cometidos por terceros y ello los ubique en una situación de especial vulnerabilidad que puede ser aprovechada por delincuentes, afectándolos de diferentes formas.

El presente trabajo se propone identificar los principales peligros digitales que enfrentan los menores al navegar libremente en Internet, y el alcance de la protección legal disponible en México en la actualidad.

Para conocer el estado del arte, el apartado II realiza una revisión de los trabajos elaborados previamente en torno a los riesgos del internet, para identificar el enfoque que han tenido y ubicar la pertinencia de la presente propuesta. 


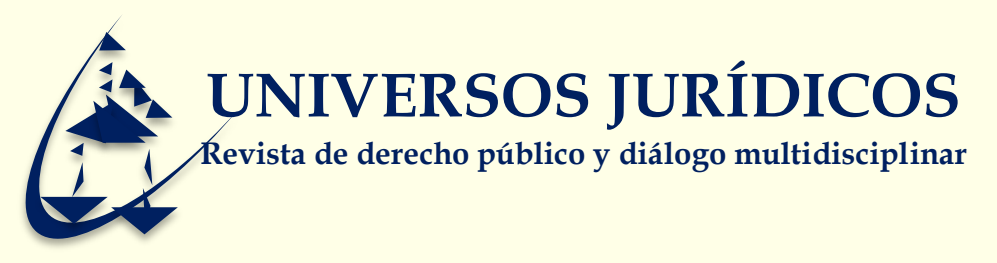

El apartado III presenta un diagnóstico del uso global de internet entre niños y adolescentes, destacando datos entre grupos de edades, tipos de equipos y nacionalidades.

El apartado IV identifica y clasifica los riesgos que existen en el uso de los medios digitales para los menores de edad.

El apartado $\mathrm{V}$ proporciona datos que refieren a las características del uso de Internet en México, tomando en cuenta específicamente los datos que arroja la Encuesta Nacional sobre Disponibilidad y Uso de Tecnología de Información en los Hogares 2019.

El apartado VI presenta la regulación nacional de los delitos en el internet contra menores haciendo una breve revisión desde sus inicios a la fecha.

El apartado VII revisa el marco regulatorio internacional de protección de los menores de los actos delictivos en línea.

Al final, se presentan las conclusiones y recomendaciones.

\section{Estudios previos}

La Internet es actualmente el medio de comunicación que mayor influencia tiene en menores, se ha reconocido como la herramienta de comunicación y educación que permite a niños y jóvenes aprender, buscar información o comunicarse con familiares o amigos y que deben aprender a manejar de manera segura para evitar afectaciones de cualquier índole (García, 2008).

Desde hace algunos años, los riesgos que acompañan el creciente uso infantil de Internet han sido estudiados desde diferentes facetas. García, López de Ayala López y García Jiménez (2014) refieren varias líneas de investigación: algunas de 


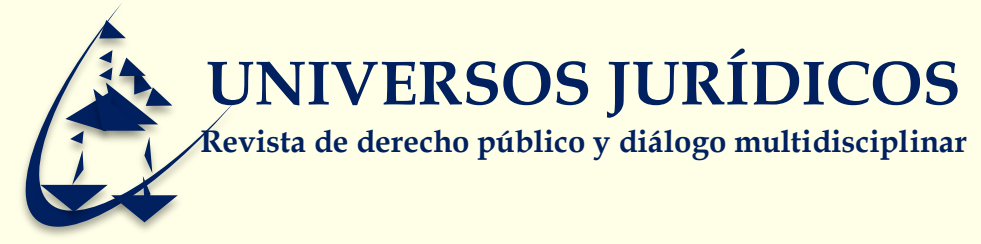

ellas se centran en el acceso, en diferentes niveles y grados; a contenidos pornográficos; de ideología racista o a contenidos violentos; otro aspecto estudiado ha sido la publicación de datos personales en el ciberespacio y en las redes sociales, así como el tema del ciberbullying. Los mismos autores refieren estudios sobre la adicción al uso problemático de Internet, el uso abusivo, uso compulsivo y uso patológico, dependencia de Internet, uso deficiente o, simplemente, adicción a Internet o ciberadicción, entre otros.

En la literatura se destaca la preocupación ante temas como el porcentaje de adolescentes que tiene la sensación de un uso no controlado, la influencia de un uso excesivo en la vida cotidiana de los adolescentes, el tiempo de exposición a Internet como factor predictivo de uso problemático o adictivo o la relación entre el uso de Internet y trastornos psiquiátricos como depresión, autoestima, angustia emocional, ansiedad y alteraciones del sueño (García, López de Ayala López y García Jiménez, 2014).

Gross y Acquisti (2005) analizaron la revelación de información y privacidad en las redes sociales a partir del análisis directo del comportamiento de más de 4000 alumnos universitarios en su uso de Facebook, que había surgido el año previo. Haciendo el seguimiento de estos investigadores, Govani y Pashley (2005) realizaron un estudio sobre el grado de conciencia de los estudiantes de las implicaciones que sobre su privacidad tiene el uso de Facebook. En relación a las motivaciones en el uso de las redes sociales, se destaca el estudio de Schaefer (2008) sobre las motivaciones y modelos de comportamiento en las redes sociales (Jiménez, 2014).

Otros estudios han señalado la edad y el género como dos variables que influyen de forma decisiva en los riesgos que los menores afrontan en la Red. Vandoninck et al. (2012) encontraron que los adolescentes que viven en hogares de menores 


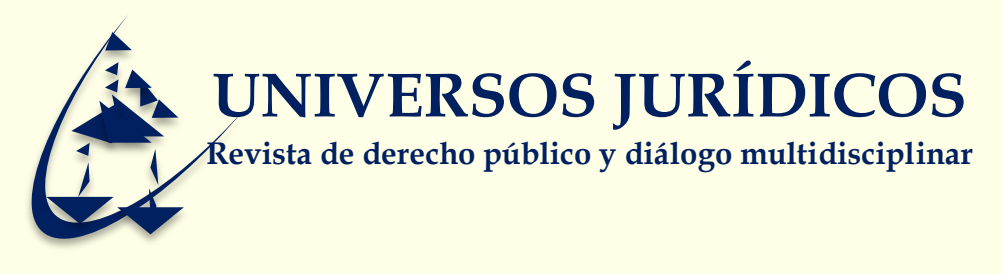

ingresos se enfrentan a más riesgos, sin embargo, la incidencia del estatus socioeconómico sobre los riesgos online de los menores ha sido escasamente analizada (García, López de Ayala López y García Jiménez, 2014).

En España en particular, la comunidad científica ha estudiado los riesgos que acompañan el creciente uso infantil de Internet y los peligros que amenazan a los menores relativos a la Web y las nuevas herramientas de comunicación online. A nivel gubernamental, el Plan Contigo de la Policía Nacional y la Guardia Civil del Ministerio del Interior (2011) analiza la seguridad en Internet, identificando las nuevas amenazas que han surgido especialmente para los jóvenes en el uso de Internet (Jiménez, 2014).

Por último, destaca el posicionamiento claro del gobierno de los Estados Unidos de América, de cuyo país proceden las mayores empresas que gestionan las redes sociales más utilizadas a nivel mundial y que a través del Federal Bureau of Investigación (2012), en un documento sobre los riesgos de las redes sociales virtuales, advierte que en cuanto más información se comparta mayor es la vulnerabilidad a la que los usuarios quedan expuestos, incluso aplicando altas restricciones en las configuraciones de seguridad de las redes sociales (Jiménez, 2014).

\section{El uso global de Internet entre niños y adolescentes}

El uso de internet ha crecido en mayor medida, desplazando a la televisión, y con ello, su influencia, como medio de comunicación, hoy por hoy es mayor en niños y jóvenes en todo el mundo. Según UNICEF (2017), los jóvenes, entre 15 a 24 años, son el grupo de edad más conectado. En todo el mundo, el $71 \%$ están en línea, en comparación con el $48 \%$ de la población total. Los niños y adolescentes menores de 18 años representan aproximadamente uno de cada tres usuarios de internet en todo el mundo. Algunos estudios revelan que los niños están 


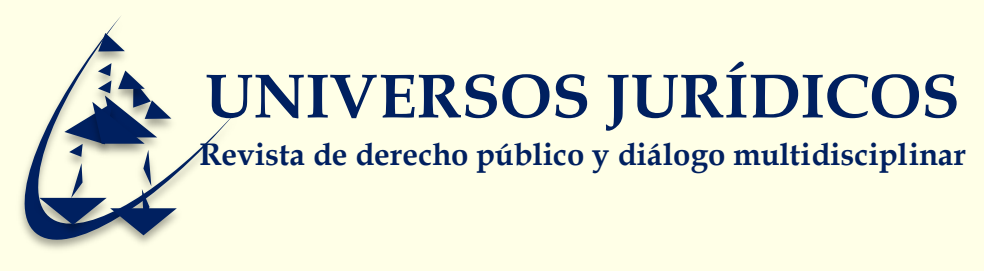

accediendo a internet a edades cada vez más tempranas. Los teléfonos celulares están promoviendo una "cultura del dormitorio", y para muchos niños el acceso a la internet es cada vez más personal, tiene un carácter más privado y está menos supervisado.

Según la Comisión Económica para América Latina (CEPAL, 2014), Internet es usado por niños y adolescentes sobre todo para obtener información y comunicarse; lo utilizan para buscar contenidos relevantes para sus estudios, para socializarse, visitar las redes sociales, descargar música y películas y entretenerse con videojuegos en línea. En general, este grupo social accede a Internet desde el hogar (49\%) y la escuela (46\%). Sin embargo, si se analiza el acceso de una forma más pormenorizada, parecen existir importantes diferencias en los lugares de acceso según país.

Según Sánchez-Teruel y Robles-Bello (2016), en Colombia, los niños y adolescentes lo usan mayoritariamente en la escuela, a diferencia de Costa Rica (56\%), México (60\%), Ecuador (64\%), Perú (67\%) y El Salvador $(81 \%)$ donde se utiliza en el hogar. En Chile, casi el $80 \%$ de los adolescentes con edades entre 13 y 18 años tiene teléfono móvil, porcentaje que baja al 65\% en El Salvador y al $64 \%$ en México. En Brasil, las cifras de uso de redes sociales e Internet de niños desde los 9 a los 16 años superan a las de sus iguales europeos. Todos estos datos confirman que el desarrollo digital en América Latina va creciendo exponencialmente ante una constante demanda social. Por su parte, en Estados Unidos, algunos estudios revelan que tan pronto los adolescentes poseen un teléfono inteligente, más del $90 \%$ lo utiliza para conectarse con redes sociales. Incluso sin poseer un dispositivo móvil muy avanzado, el $77 \%$ de los adolescentes se registra en redes sociales, y en general, casi el 50\% envía mensajes de texto o WhatsApp a diario a sus amigos. Por otra parte, muchos niños y adolescentes estadounidenses emplean métodos multifacéticos para comunicarse con sus 


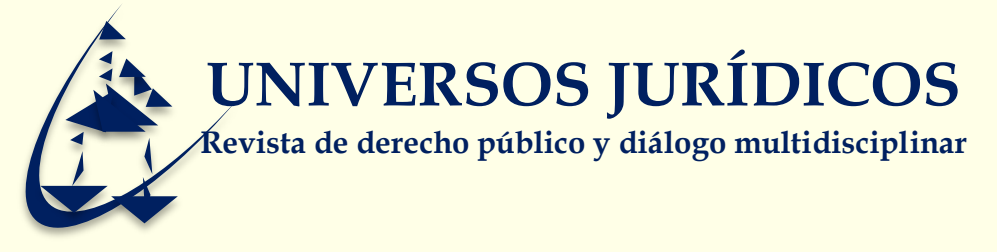

compañeros y amigos, incluido Internet, mensajería instantánea y sitios de redes sociales. Según un informe de 2013 sobre el uso de los medios sociales y la tecnología móvil, investigadores del Pew Internet y American Life Project encontraron que el $95 \%$ de los niños y adolescentes encuestados utilizaba internet, una cifra que se había mantenido constante en los Estados Unidos desde el año 2006.

En el caso específico de Europa, se detectó que una gran mayoría de los hogares en la Unión Europea de los 27 países hacen uso diario de Internet, pero se observan diferencias significativas en el acceso y utilización entre los países. Las acciones de los individuos que utilizan Internet regularmente estaban por encima de la media europea (sobre un $80 \%$ ) en seis Estados miembros: Suecia, Dinamarca, Luxemburgo, Países Bajos, Finlandia y Reino Unido. Las acciones digitales estaban por debajo del $60 \%$ en siete Estados miembros: Bulgaria, Grecia, Italia, Chipre, Polonia, Portugal y Rumanía. Según el estudio, el porcentaje de usuarios habituales de Internet entre las personas más jóvenes (1624 años) fue del $91 \%$, mientras que era solo del $40 \%$ para el grupo de edad entre los 55-74 años. Básicamente, 9 de cada 10 europeos de 16-24 años utiliza Internet regularmente. Se estima que no existen grandes diferencias entre hombres y mujeres que utilizan internet a diario ( $70 \%$ hombres y el $65 \%$ mujeres) (Sánchez-Teruel y Robles-Bello, 2016).

En 2017, en España, el 88,4\% de los niños de 10 años utilizaban equipo de cómputo y el $88.8 \%$ usaba internet, unos datos que sugieren que su uso es ya mayoritario antes de esa edad, si bien en el caso del móvil no es hasta los 13 años cuando su uso se extiende. En general, la proporción del uso de tecnologías de la información y la comunicación por los niños de 10 a 15 años se registra muy elevada y los usuarios de equipos de cómputo de esas edades se estiman en un 92.4\%; los de internet, un $95.1 \%$ y los de teléfonos móviles, un $69.1 \%$. El uso del 


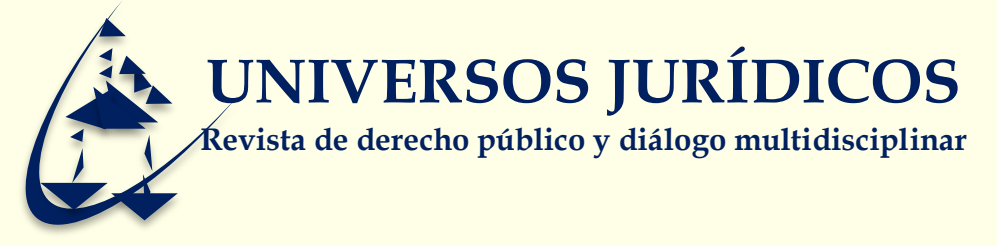

ordenador e internet se incrementa entre los 10 y los 15 años hasta alcanzar a esta última edad el $92,5 \%$ y el $99.2 \%$, respectivamente. En cuanto al teléfono móvil, a los diez años sólo un $25 \%$ de los niños de esa edad lo usa, aunque a los 11 años pasan a tenerlo un $45.2 \%$; a los doce, un $75 \%$; a los trece, un $83.2 \%$; a los catorce, un $92.8 \%$, y a los quince, un $94 \%$, de forma que desde los catorce años nueve de cada diez niños disponen de móvil. Por sexo, las diferencias en el uso de equipos de cómputo y de internet son pocos significativas, aunque las mujeres aventajan a los hombres. Un $93,9 \%$ de las chicas de entre diez y quince años usa ordenador, frente a un $91,1 \%$ de los hombres, mientras que un $95,2 \%$ de las menores utiliza internet frente a un $94,9 \%$ de los hombres. También son más las niñas y jóvenes que tienen teléfono móvil, un $70 \%$ frente a un $68,2 \%$ de los chicos. Además, el 95,1\% de los menores de edad que residen en España navega por Internet y el 92,4\% hace uso del ordenador. La investigación señala también que, de los que utilizan el ordenador, un $93,9 \%$ son chicas, frente al $91,1 \%$ que son chicos. También las menores utilizan más Internet $(95,2 \%)$ que los chicos (94,9\%). Por edades, los resultados sugieren que el uso de ordenador e Internet es una práctica mayoritaria en edades anteriores a 10 años (RTVE, 2017).

\section{Los riesgos para los menores en el uso de los medios digitales}

Las prácticas y el comportamiento de los menores en la red pueden facilitar la comisión de actos delictivos por parte de terceros, lo cual los sitúan en casos de especial vulnerabilidad que pueden ser aprovechados por cualquier persona y llegar a convertirlos en víctimas de delitos. Generalmente, los menores acceden a Internet desde sus casas mediante equipos que no disponen de sistemas de protección, y esto aunado a la desinformación que tienen sobre las normas básicas de seguridad a la hora de utilizarlo, ya que los exponen a situaciones que les hacen ser tan vulnerables. 


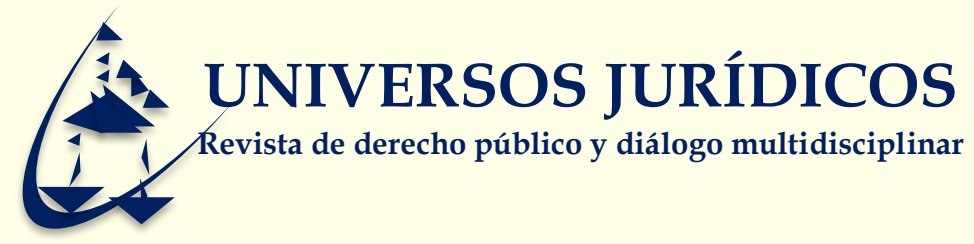

Según la UNICEF (2017), actualmente los investigadores suelen clasificar la gran variedad de riesgos que aparecen en línea en tres categorías:

a) Riesgos de contenido: Cuando un niño está expuesto a un contenido no deseado e inapropiado. Esto puede incluir imágenes sexuales, pornográficas y violentas; algunas formas de publicidad; material racista, discriminatorio o de odio; y sitios web que defienden conductas poco saludables o peligrosas, como autolesiones, suicidio y anorexia.

b) Riesgos de contacto: Cuando un niño participa en una comunicación arriesgada, como por ejemplo con un adulto que busca contacto inapropiado o se dirige a un niño para fines sexuales, o con personas que intentan radicalizar a un niño o persuadirlo para que participe en conductas poco saludables o peligrosas.

c) Riesgos de conducta: Cuando un niño se comporta de una manera que contribuye a que se produzca un contenido o contacto riesgoso. Esto puede incluir que los niños escriban o elaboren materiales odiosos sobre otros niños, inciten al racismo o publiquen o distribuyan imágenes sexuales, incluido el material que ellos mismos produjeron.

Desde otra perspectiva, también García-Piña $(2008,273)$ clasifica los riesgos que existen al navegar libremente en Internet, en relación a los servicios utilizados:

a) Página web: Los riesgos a los que se exponen niños y adolescentes cuando navegan libremente por Internet, son el acceso a páginas de contenido para adultos con material sexual explícito. También pueden encontrar contenidos de juegos, apuestas, escenas de violencia, consumo de drogas y alcohol, etc. En paralelo, los juegos de dinero (casinos, loterías y sistemas piramidales) o cualquier otro para ganar dinero fácilmente, les puede crear adicción. Otro riesgo es la comunicación con personas desconocidas que pueden engañar, seducir, abusar e inclusive desarrollar acciones ilícitas contra ellos, solicitando información personal como nombre, dirección, teléfono, aficiones, datos de la familia, etc.

b) Blog: Este sitio web se actualiza periódicamente; recopila información personal y funciona como un diario en línea. En él se escriben datos sobre la vida personal de cada usuario y de esta manera los niños y los adolescentes pueden construir sus propios diarios electrónicos gratis. Es un sitio visitado frecuentemente por depredadores en línea.

c) "Chat": Permite comunicarse con personas en cualquier parte del mundo. En esta variante el riesgo para el usuario infantil y juvenil se incrementa debido a que, al estar conversando fácilmente, olvidan que se trata de un lugar público; no necesariamente se conoce la verdadera identidad de los participantes y la mayoría de "chats" no están supervisados, es decir, no hay vigilancia ni control.

d) Mensajería instantánea o "Messenger": Actualmente es el servicio más usado por niños y adolescentes. El envío de mensajes instantáneos permite establecer conversaciones de texto en tiempo real con otras personas de una "lista de contactos". En este caso la conversación es entre dos personas y puede ser más segura porque se puede controlar la lista de contactos,

UNIVERSIDAD VERACRUZANA.

Instituto de Investigaciones Jurídicas

http://universosjuridicos.uv.mx/index.php/univerjuridicos/index

Xalapa, Veracruz, México 


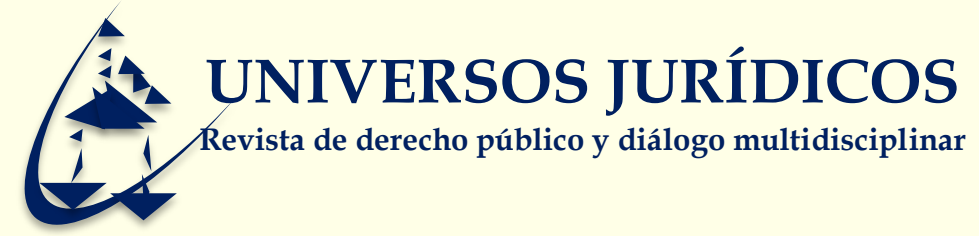

reduciéndola a los amigos y familiares. Este medio permite activar la webcam (cámara web) para establecer contacto visual y conversaciones. La justificación para el uso de la webcam se limita a la comunicación con un familiar o por motivos de trabajo; fuera de ello, no es recomendable su uso. Uno de los riesgos más importantes es que la webcam se puede "troyanizar", es decir, cualquier persona puede tomar el control de la computadora a través de la cámara conectada a Internet y entrar a los hogares o ser utilizado por depredadores en línea.

e) Correo electrónico: En esta modalidad los menores se comunican y reciben información 0 mensajes de otras personas. Pueden recibir mensajes comerciales no deseados (mensajes de correo basura o "spam") o el inconveniente de que algún desconocido intente establecer una relación inadecuada o que el menor sea amenazado o acosado por esta vía.

f) Foros: Son áreas de Internet para grupos de discusión e intercambio de ideas sobre varios temas: música, deportes, profesiones, escuelas, etc., aunque se pueden tratar temas que no son adecuados para los niños, tales como sexo, drogas, violencia, etc.

García-Piña (2008), como médico pediatra, especialista en violencia infantil, identifica claramente los riesgos específicos que pueden sufrir los menores al hacer uso de los medios digitales y ubica la exposición de material pornográfico, como primer riesgo digital. Reconoce que los caminos que llevan al conocimiento de la sexualidad en los niños no siempre se originan en la familia y en la escuela. En la actualidad, la información extra familiar ofrecida en el proceso de aprendizaje hace que niñas y niños se encuentren, cada vez a menor edad, expuestos a manifestaciones erróneas, distorsionadas y en muchos casos incomprensibles acerca de la sexualidad. Admite que en la Internet existe un abuso de temas y expresiones sexuales a los cuales pueden acceder los niños y adolescentes. Ello puede acelerar la sexualidad y generar problemas como la adicción a la Internet, que requieren atención psicológica. Explica que frecuentemente, el primer contacto con la pornografía puede ocurrir accidentalmente, al navegar en línea durante la realización de una tarea o bien recibir un correo (SPAM) pornográfico por e-mail o mensajería instantánea. Ocasionalmente se puede obtener durante una búsqueda intencional. 


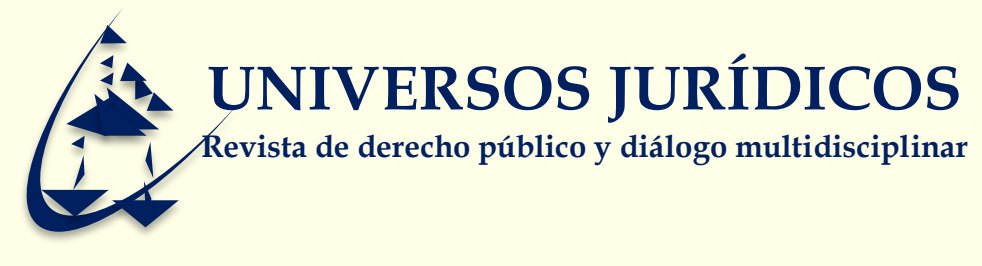

García-Piña afirma que, si dejamos al margen la natural curiosidad sexual que motiva esta búsqueda en los adolescentes y que generalmente no tiene mayores consecuencias, el problema reside en la facilidad para acceder a páginas con contenidos sexuales de diferente índole; frecuentemente esta exposición puede tener repercusiones negativas en el comportamiento sexual de niños y jóvenes. En estos casos, debe tenerse presente que una conducta placentera es susceptible de convertirse en adicción; ello depende de su intensidad, frecuencia y grado de interferencia con las relaciones familiares, sociales, laborales 0 escolares de la persona implicada y puede tener un impacto negativo en el funcionamiento psico-emocional y social del individuo. Señala que los adolescentes pueden tener cambios de conducta relacionadas al uso problemático o compulsivo de la Internet, como la suspensión de actividades anteriormente satisfactorias: deporte, juegos, salir con amigos o su pareja, actividades en familia; aparecen entonces problemas de concentración, bajo rendimiento escolar o aislamiento. El menor invierte cada vez más tiempo navegando en Internet y presenta cambios de conducta cuando no le es posible su acceso. En algunos casos puede haber ansiedad y depresión (García-Piña, 2008).

El segundo riesgo específico que identifica García-Piña (2008), es el abuso y corrupción de menores. Los medios de comunicación que disponen los niños y jóvenes permiten tener contacto con personas en todo el mundo, lo que favorece la cesión de datos personales, citas con desconocidos y comunicación con personas que aprovechan la red para actividades ilícitas. Asegura que los jóvenes más vulnerables son los que tienen conflictos familiares, baja autoestima, antecedente de maltrato infantil o violencia familiar, depresión y búsqueda de atención o afecto en otras personas. Esta realidad puede poner a niños y jóvenes en riesgo potencial de encontrarse con depredadores en línea, quienes pueden encubrir su edad, estado civil, sexo e identidad. El anonimato que proporciona el 


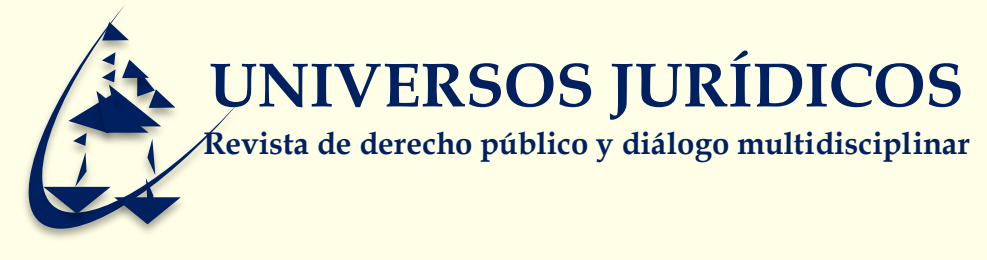

Internet propicia que la confianza y la intimidad se desarrollen rápidamente, principalmente con gente joven y poco experimentada, que requieran atención, afecto, amabilidad e incluso, regalos. Es frecuente que pidan mantener la relación en secreto y muestren de manera paulatina, material sexual. Esta herramienta es ideal para pedófilos y pederastas.

\section{Las características del uso de internet en México}

Según el Instituto Federal de Telecomunicaciones (2020) y de acuerdo al análisis de los resultados de la Encuesta Nacional sobre Disponibilidad y Uso de Tecnología de Información en los Hogares 2019, en México hay 80.6 millones de usuarios de Internet, que representan el $70.1 \%$ de la población de seis años o más. Esta cifra revela un aumento de 4.3\% respecto de la registrada en 2018 $(65.8 \%)$ y de $12.7 \%$ respecto a 2015 (57.4\%). De acuerdo al comportamiento de los distintos grupos de edad de la población total, el que concentra la mayor proporción de usuarios de Internet, es el grupo de 18 a 24 años con una participación del $91.2 \%$. El segundo grupo de edad donde el uso de Internet está más generalizado, es el de 12 a 17 años, con $87.8 \%$. En tercer lugar, se encuentran los usuarios de 25 a 34 años, quienes registraron $86.9 \%$. Por su parte, el grupo de edad que menos usa Internet es el de 55 y más años, ya que registraron $34.7 \%$. Considerando los ámbitos urbano y rural, la encuesta estima que el $76.6 \%$ de los usuarios de Internet, respecto de la población total de seis años o más, está concentrada en la zona urbana y el $47.7 \%$ en la rural. Entre 2017 y 2019 , los usuarios en la zona urbana pasaron de $71.2 \%$ a $76.6 \%$, mientras que en la zona rural el incremento fue de $39.2 \%$ a $47.7 \%$ de usuarios de 6 años o más. Respecto de la distribución poblacional por sexo, se observa que de los 80.6 millones de usuarios de Internet de seis años o más, el $51.6 \%$ son mujeres y el $48.4 \%$ son hombres.

\footnotetext{
UNIVERSIDAD VERACRUZANA.

Instituto de Investigaciones Jurídicas

http://universosjuridicos.uv.mx/index.php/univerjuridicos/index

Xalapa, Veracruz, México
} 


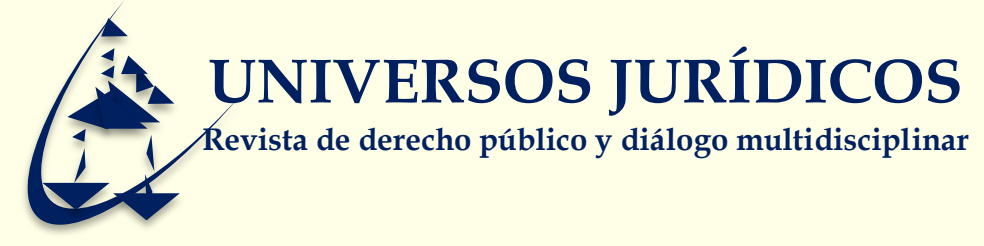

Tomando en cuenta los dispositivos utilizados para conectarse a Internet, en 2019, la ENDUTIH da a conocer que el $95.3 \%$ de los usuarios de Internet se conectaron a través de un celular inteligente (Smartphone), el 33.2\% lo hizo por medio de una computadora portátil, el $28.9 \%$ utilizó una computadora de escritorio, el $23.4 \%$ de los usuarios de Internet se conectó a través de un televisor con acceso a Internet (Smart TV) o algún dispositivo conectado a esta, el 17.8\% por medio de una Tablet y un $8.4 \%$ a través de una consola de videojuegos. Entre las principales actividades de los usuarios de Internet en 2019, están para entretenimiento (91.5\%), obtención de información (90.7\%) y comunicarse (90.6\%). En contraste, las actividades que menos realizan los usuarios de Internet son operaciones bancarias en línea (16.8\%), ordenar o comprar productos (22.1\%) e interactuar con el gobierno (35.6\%). La ENDUTIH también capta la disponibilidad y uso de la telefonía celular, que se ha constituido como una de las tecnologías de mayor uso entre la población. En este sentido, la encuesta estima que en 2019 se cuenta con 86.5 millones de usuarios de esta tecnología, lo que representa que el $75.1 \%$ de la población de seis años o más y un incremento de $3.6 \%$ respecto de 2015 (IFT, 2020).

De acuerdo con los resultados de la ENDUTIH 2019, nueve de cada diez usuarios de teléfono celular disponen de un celular inteligente (Smartphone), por medio del cual tienen la posibilidad de conectarse a Internet. Entre 2018 y 2019, el número total de usuarios que sólo dispusieron de un celular inteligente tuvo un crecimiento de $9.5 \%$, es decir, que pasó de 69.6 millones de personas a 76.2 millones. Esto significa que, entre los dos años, la diferencia porcentual de usuarios de este tipo de teléfonos fue de $4.3 \%$, pues en 2018 representaban el $83.8 \%$ y en 2019 el 88.1\% (IFT, 2020).

Respecto de la distribución de usuarios de telefonía celular en los ámbitos urbano y rural, la encuesta estima que para 2019, el porcentaje de usuarios de esta 


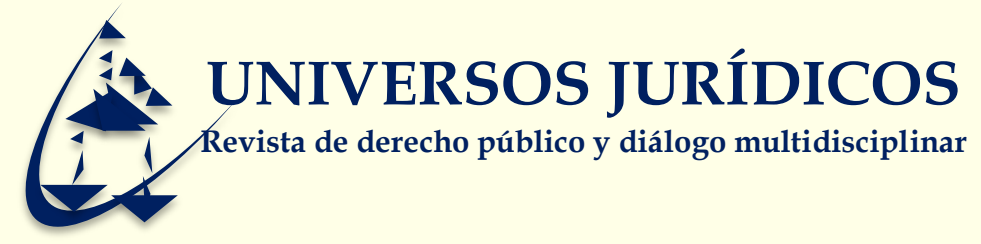

tecnología en el área urbana es de $79.9 \%$, lo que corresponde a 71.2 millones de usuarios, que representa un incremento del 1.1\% respecto del año 2018. Mientras que, en el área rural, el porcentaje de usuarios de esta tecnología es de $58.9 \%$, lo que corresponde a 15.3 millones de usuarios, siendo esta ultima la que presenta una mayor variabilidad respecto del año anterior, al incrementarse un 3.8\%. Por otra parte, la encuesta señala que en 2019 hay un aumento de los usuarios que se conectan a Internet desde un celular inteligente (Smartphone), pasando del 93.4\% en 2018 a $94.7 \%$ en 2019, con una diferencia de 7.3 millones de personas. La conexión a Internet por medio de datos es la más utilizada y representa el $90.6 \%$ de los usuarios de celular inteligente (Smartphone), mientras que el $9.4 \%$ restante se conecta a Internet solo por Wifi (IFT, 2020).

En 2019, la ENDUTIH estima que 48.3 millones de los usuarios de Internet mediante celular inteligente (Smartphone) instalaron aplicaciones en sus teléfonos. De estos, el $86.4 \%$ instaló aplicaciones de mensajería instantánea, el $80.8 \%$ para acceder a redes sociales y el $69.6 \%$ instaló aplicaciones para acceder a contenidos de audio y video. En ese mismo año, los usuarios de computadora de seis años o más alcanzaron los 49.4 millones, lo que representa un $43.0 \%$ del total de la población en este rango de edad. Asimismo, el porcentaje de usuarios de computadora observado es menor en 2.0 puntos porcentuales respecto del registrado en 2018. La proporción de hogares que disponen de computadora registró un descenso marginal, al pasar de un valor de $44.9 \%$ en 2018 a $44.3 \%$ en 2019, lo que significa una reducción de 0.6 puntos porcentuales (IFT, 2020).

Los televisores son los bienes de mayor uso en los hogares, ya que en 2019 el 92.5\% tenía al menos uno. Respecto del tipo de televisor disponible en los hogares, la ENDUTIH revela que el $76.5 \%$ de ellos cuentan con al menos uno de tipo digital, lo que representó un aumento de 3.6 puntos porcentuales respecto de 2018. Tomando en cuenta que todos los hogares con televisor digital están 


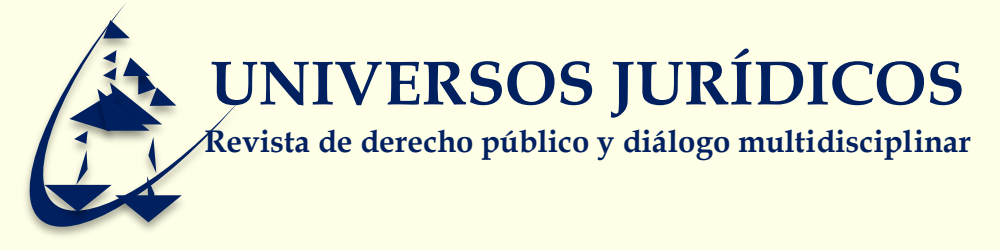

habilitados para recibir señales abiertas, otro conjunto de interés es aquel que, aunque sólo dispone de televisor analógico, cuenta con señal de televisión de paga que le permite recibir señales digitales; los resultados de la ENDUTIH 2019 arrojaron que estos representan un $8.7 \%$ de los hogares con acceso a la señal digital. Por su parte, los hogares que cuentan con un televisor analógico y reciben señal por medio de un decodificador representan un 5.1 por ciento del total. De esta manera, el $96.0 \%$ de los hogares del país reciben la señal de televisión digital a partir de alguno de los tres medios mencionados anteriormente: televisor digital, señal de televisión de paga o decodificador (IFT, 2020).

\section{La regulación nacional de los delitos contra menores}

El uso de Intente ha ofrecido muchas ventajas a la sociedad, considerando el comercio de bienes y servicios, así como la conectividad para ampliar la educación y cultura a los lugares más alejados de la civilización. Sin embargo, el uso se ha extendido incluso para fines nocivos o para la comisión de delitos, debido principalmente a la ausencia de reglas suficientemente claras.

El primer marco jurídico para regular la red en México se dio en mayo de 1999, cuando se incluyeron en el Código Penal Federal los conceptos de delitos informáticos por acceso a sistemas particulares, de gobierno y del sector financiero. En enero del 2000, se publicaron dos nuevas leyes: la Ley de Obras Públicas y Servicios y la Ley de Arrendamientos, Adquisiciones y Servicios del Sector Público para normar al sistema Compra net. Para el mes de mayo se reformaron cuatro leyes en materia de comercio electrónico: Código de Comercio, Código Civil Federal, Código Federal de Procedimientos Civiles y Ley Federal de Protección al Consumidor con el fin de validar contratos electrónicos y proteger al consumidor en operaciones en línea. El problema es que este tipo de reglamentación se orientó más a la protección de los intercambios comerciales 


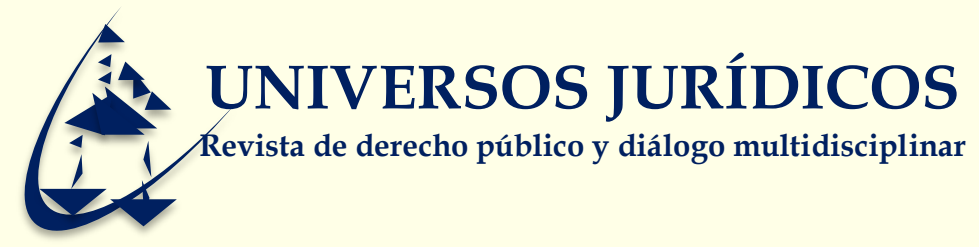

entre las empresas, que a la protección para los usuarios o ciudadanos (Duran, 2010).

En el caso particular de delitos cometidos en contra de menores, se reformó el Código Penal Federal (DOF, 2007), estableciendo en su Capítulo II, de la Corrupción de menores e incapaces; pornografía infantil y prostitución sexual de menores, lo siguiente:

Articulo 201.- Comete el delito de corrupción de menores, el que induzca, procure, facilite $u$ obligue a un menor de dieciocho años de edad o a quien no tenga capacidad para comprender el significado del hecho, a realizar actos de exhibicionismo corporal, lascivos o sexuales, prostitución, ebriedad, consumo de narcóticos, prácticas sexuales o a cometer hechos delictuosos. Al autor de este delito se le aplicaran de cinco a diez años de prisión y de quinientos a dos mil días multa.

Al que obligue o induzca a la práctica de la mendicidad, se le impondrá de tres a ocho años de prisión y de cincuenta a doscientos días multa.

No se entenderá por corrupción de menores los programas preventivos, educativos o de cualquier índole que diseñen e impartan las instituciones públicas, privadas o sociales que tengan por objeto la educación sexual, educación sobre función reproductiva, la prevención de enfermedades de transmisión sexual y el embarazo de adolescentes, siempre que estén aprobados por la autoridad competente.

Cuando de la práctica reiterada de los actos de corrupción el menor o incapaz adquiera los hábitos del alcoholismo, farmacodependencia, se dedique a la prostitución o a formar parte de una asociación delictuosa, la pena será de siete a doce años de prisión y de trescientos a seiscientos días multa.

Si además de los delitos previstos en este capítulo resultase cometido otro, se aplicarán las reglas de la acumulación.

Artículo 201 bis. - Al que procure o facilite por cualquier medio el que uno o más menores de dieciocho años, con o sin su consentimiento, lo o los obligue o induzca a realizar actos de exhibicionismo corporal, lascivos o sexuales, con el objeto y fin de video grabarlos, fotografiarlos o exhibirlos mediante anuncios impresos o electrónicos, con o sin el fin de obtener un lucro, se le impondrán de cinco a diez años de prisión y de mil a dos mil días multa.

Al que fije, grabe, imprima actos de exhibicionismo corporal, lascivos o sexuales en que participen uno o más menores de dieciocho años, se le impondrá la pena de diez a catorce años de prisión y de quinientos a tres mil

UNIVERSIDAD VERACRUZANA.

Instituto de Investigaciones Jurídicas

http://universosjuridicos.uv.mx/index.php/univerjuridicos/index

Xalapa, Veracruz, México 


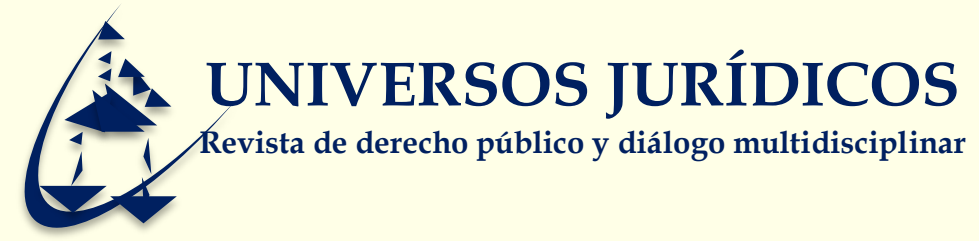

días multa. La misma pena se impondrá a quien con fines de lucro o sin él, elabore, reproduzca, venda, arriende, exponga, publicite o transmita el material a que se refieren las acciones anteriores.

Se impondrá prisión de ocho a dieciséis años y de tres mil a diez mil días multa, así como el decomiso de los objetos, instrumentos y productos del delito, a quien por sí o a través de terceros, dirija, administre o supervise cualquier tipo de asociación delictuosa con el propósito de que se realicen las conductas previstas en los dos párrafos anteriores con menores de dieciocho años.

Para los efectos de este artículo se entiende por pornografía infantil, la representación sexualmente explicita de imágenes de menores de dieciocho años.

Artículo 201 Bis 1.- Si el delito de corrupción de menores o de quien no tenga capacidad para comprender el resultado del hecho o el de pornografía infantil es cometido por quien se valiese de una función pública que tuviese, se le impondrá hasta una tercera parte más de las penas a que se refieren los artículos 201 y 201 bis y destitución del empleo, cargo o comisión públicos e inhabilitación para desempeñarlo, hasta por un tiempo igual al de la pena impuesta para ejercer otro.

Artículo 201 Bis 2.- Si el delito es cometido con un menor de dieciséis años de edad, las penas aumentaran hasta una tercera parte más de las sanciones a que se refieren los artículos 201 y 201 bis. Si el delito se comete con menor de doce años de edad, las penas aumentaran hasta una mitad de las sanciones a que se refieren los artículos 201 y 201 bis de esta Ley.

Artículo 201 Bis 3.- Al que promueva, publicite, invite, facilite o gestione por cualquier medio a persona o personas a que viaje al interior o exterior del territorio nacional y que tenga como propósito, tener relaciones sexuales con menores de dieciocho años de edad, se le impondrá una pena de cinco a catorce años de prisión y de cien a dos mil días multa.

Según considera Cassou (2009), en nuestro país se sanciona por la ley penal la pornografía infantil mediante anuncios electrónicos. El problema a dilucidar en este caso, es que el órgano encargado de investigar y perseguir las conductas delictuosas (Ministerio Publico) esté en aptitud de iniciar la averiguación previa con el suficiente soporte técnico, puesto que en el mayor de los casos, se debe enfrentar bandas que conforman delincuencia organizada y que pueden estar ubicados físicamente en un país diverso, a lo que se suma el derecho establecido en la Constitución de no intervenir en las comunicaciones privadas, que se 


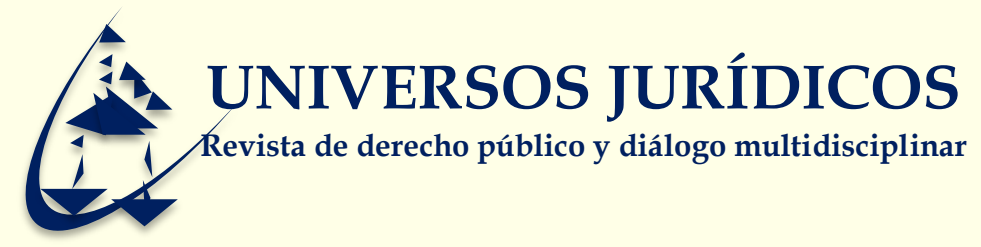

traduce en que se requiere autorización judicial por parte de un Juez de Distrito para escuchar y ver tales imágenes a que accede un usuario de Internet.

Reyna (2002), por su parte, señala que el fenómeno de la pornografía en Internet se engloba dentro de los denominados delitos computacionales, al suponer una nueva manifestación del delito ofensas al pudor, cuya comisión afecta el bien jurídico de la libertad sexual.

Finalmente, para el caso mexicano, el International Centre for Missing \& Exploited Children $(2016,32)$ evaluó el marco nacional legislativo que aborda el tema de la pornografía infantil, considerando los siguientes seis criterios:

1) Que la legislación nacional exista con especial consideración hacia la pornografía infantil,

2) Que proporcione una definición de pornografía infantil

3) Que tipifique los delitos facilitados por la informática

4) Que tipifique como delito la posesión intencional de pornografía infantil, independientemente de la intención de distribuirla

5) Que solicite a los proveedores de servicios de Internet que denuncien a la policía, o a algún otro organismo encargado, cualquier sospecha de actividades relacionadas con la pornografía infantil, y

6) Que la legislación nacional ordene que los proveedores de servicios de Internet desarrollen e implementen disposiciones para la retención y preservación de datos.

De los cuales, según los hallazgos de la última investigación, la legislación mexicana cubre con la mayoría de los criterios excepto el número 5. El International Centre for Missing \& Exploited Children considera en ese punto que se debe exigir a los profesionales de atención médica y servicios sociales, a maestros, agentes de las fuerzas de seguridad, reveladores de fotos, profesionales en tecnologías de información, proveedores de servicios de internet, compañías de tarjetas de crédito y bancos, que acudan a la policía o a otro organismo a denunciar sobre cualquier en caso en el que haya sospechas de pornografía infantil (ICMEC, 2016). 


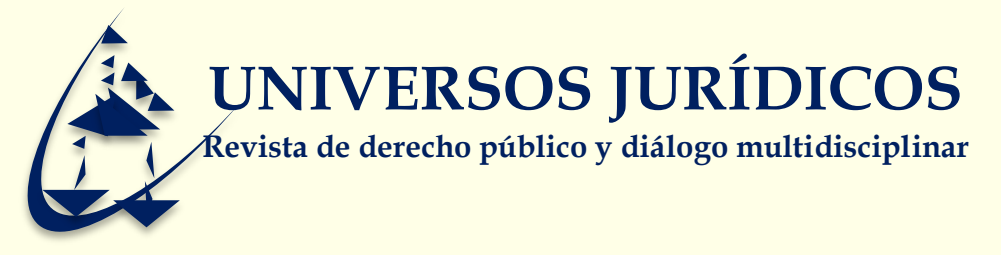

\section{El marco regulatorio internacional de protección de los menores}

La protección infantil de actos delictivos, tales como los abusos sexuales y la explotación sexual de los niños relacionada con las actividades en línea, coinciden en algunas normas internacionales. Algunos instrumentos internacionales se centran en los abusos sexuales y la explotación sexual como una violación de los derechos del niño, en el contexto más amplio de la promoción y la protección de los derechos de la infancia y su interdependencia e indivisibilidad. Por otro lado, varios instrumentos internacionales buscan combatir diversas formas de delincuencia transnacional $y$, aunque tienen en cuenta los derechos humanos de las personas afectadas, tienden a centrarse más en la respuesta y la sanción judicial (UNICEF, 2012).

Desde los años noventa, la Organización de las Naciones Unidas y sus organismos conexos, así como varios programas regionales han asumido compromisos adicionales y han adoptado directrices y códigos de conducta destinados a fortalecer los mecanismos de protección de los menores de edad. Los progresos se aceleraron en 1990, cuando la Comisión de Derechos Humanos decidió nombrar un Relator Especial sobre la venta de niños, la prostitución infantil y la utilización de niños en la pornografía; sumado a la adopción de la Comisión de Derechos Humanos de un Programa de Acción en 1992; y posteriormente los tres Congresos mundiales contra la explotación sexual comercial de los niños (Estocolmo 1996; Yokohama 2001; Río de Janeiro 2008), que reafirmaron el objetivo de una protección universal de los niños basada en los derechos humanos contra todas las formas de explotación sexual (UNICEF, 2012).

En este contexto, los cinco principales instrumentos internacionales son:

1) Convención sobre los Derechos del Niño (1989). 


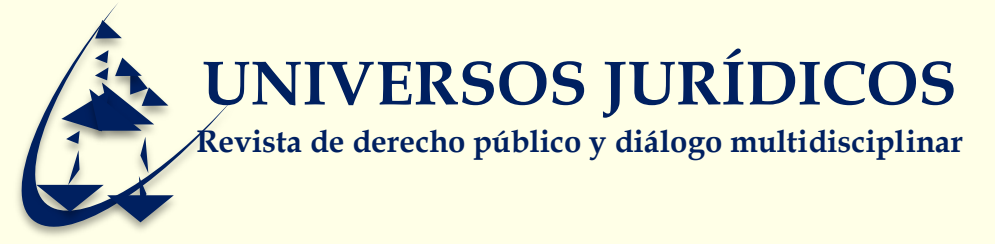

2) Protocolo Facultativo de la Convención sobre los Derechos del Niño relativo a la venta de niños, la prostitución infantil y la utilización de niños en la pornografía (PFVN, 2000).

3) Protocolo para prevenir, reprimir y sancionar la trata de personas, especialmente mujeres y niños, que complementa la Convención de las Naciones Unidas contra la Delincuencia Organizada Transnacional ("Protocolo de Palermo", 2000).

4) Convenio del Consejo de Europa sobre la Ciberdelincuencia (2001).

5) Convenio del Consejo de Europa sobre la protección de los niños contra la explotación y el abuso sexual (2007).

Estos instrumentos proporcionan las pautas para afrontar y contener la explotación sexual y los abusos sexuales de los niños en el entorno en línea, y también establecen una serie de obligaciones jurídicamente vinculantes para los Estados partes de adoptar medidas específicas a este respecto. En conjunto, integran un marco global sobre los derechos del niño que incluye las definiciones de los delitos y las disposiciones que exigen el castigo de la conducta tipificada como delito, y permiten enjuiciar de manera más eficaz a los delincuentes. Aunque los instrumentos regionales tienen aplicación concreta solamente en la región en la que han sido creados, establecen normas o criterios de referencia que pueden ser adoptados y cumplidos por otros países, y en algunos casos permiten la ratificación por parte de Estados que no pertenecen a la misma zona (UNICEF, 2012).

El Tercer Congreso Mundial (2008) dio lugar a la "Declaración de Río", que exhorta a los Estados a llevar a cabo acciones específicas y concretas para prevenir y evitar las imágenes de abusos sexuales de niños, y la utilización de Internet y de las nuevas tecnologías para la captación y manipulación de los niños con fines de abusos sexuales en línea y fuera de línea, así como para la producción y difusión de imágenes de abusos sexuales infantiles y otros materiales de este tipo. Sin embargo, pese a la mayor atención que se ha concedido a la explotación sexual y a los abusos sexuales de niños en el nivel internacional y al desarrollo de estos nuevos instrumentos mundiales y regionales de derechos humanos, aún no se aplican en forma sistemática ni la legislación necesaria ni las consiguientes medidas de orden nacional. Por ejemplo, en una 


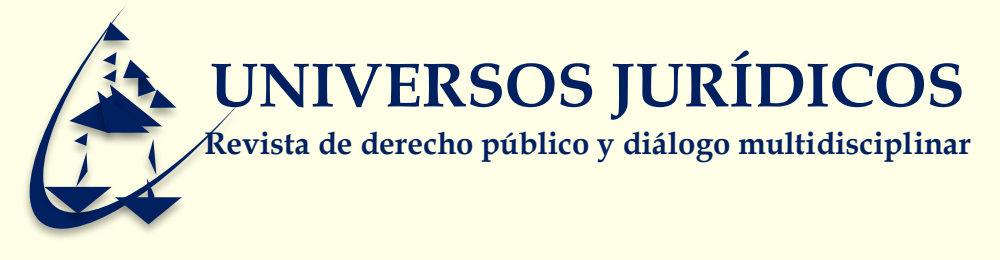

revisión de la legislación relacionada con pornografía infantil de 196 países, el International Centre for Missing \& Exploited Children (2016) señala que, para ese año, solo 82 países de contaban con legislación suficiente para combatir los delitos de pornografía infantil, y 35 países no disponían de ninguna normativa que abordara específicamente la pornografía infantil. De los países que cuentan con leyes en vigor, 60 países no definen la pornografía infantil en su legislación nacional; 26 países no proporcionan información sobre delitos cometidos mediante el uso de la computadora; y 50 no criminalizan la posesión intencional de pornografía infantil, independientemente de la intención de distribuirla (ICMEC, 2016).

A pesar de que no existen protocolos o instrumentos interamericanos específicos dirigidos a la protección de los niños en el entorno en línea y fuera de línea, existen notables recursos regionales de este tipo. El Memorándum de Montevideo, preparado en julio de 2009 por un grupo de expertos regionales, proporciona un marco para proteger la información personal de los niños en el ciberespacio. Concebido para orientar a los legisladores, jueces, responsables de la formulación de políticas y agentes del orden público sobre cómo proteger los datos personales de los niños en línea, el memorándum enumera recomendaciones sobre la prevención y la educación, los marcos jurídicos, el cumplimiento de la ley y el orden público. Aunque el memorándum no es vinculante para ningún Estado de América Latina, actúa como un marco importante para los Estados que tratan de proteger la información personal de los niños en línea (UNICEF, 2012).

\section{Conclusiones}

En virtud de que la Internet es hoy el medio de comunicación de mayor importancia entre los menores de edad, como herramienta de comunicación y entretenimiento, los riesgos 


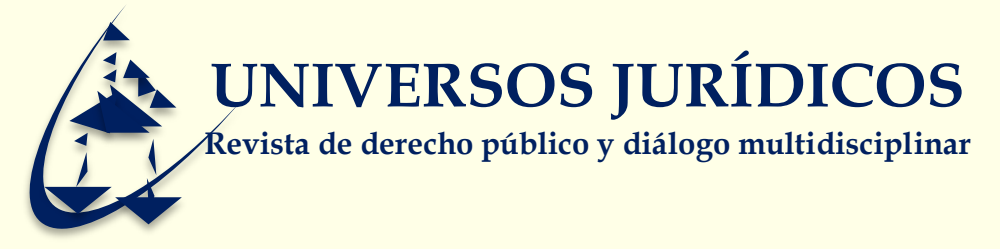

de su manejo han crecido exponencialmente, en proporción de la ampliación de la demanda de uso y las innovaciones en las aplicaciones.

El estudio nos permite entender que el mayor acceso a Internet ha sido de niños en los países industrializados, $y$, sin embargo, el resto del mundo está equiparándose debido al ritmo al que crece el consumo de la telefonía móvil. Los riesgos a los que se exponen niños y adolescentes por navegar libremente por internet son muchos, y atentan contra su salud y seguridad personales. Las nuevas tecnologías han creado una nueva dimensión en la cual la explotación sexual de los niños es el escenario más grave y que puede prosperar si no se controla.

Hasta hace no mucho, la pornografía infantil era uno de los negocios con mayor crecimiento en línea. Actualmente, la pornografía infantil en internet se ha reducido significativamente debido a los esfuerzos gubernamentales para combatir su crecimiento, sin embargo, este contenido ahora circula entre individuos y grupos a través de las redes. El problema persiste y requiere una legislación contra la pornografía infantil en todos los países, a fin de erradicarla. International Centre for Missing \& Exploited Children ya lo ha señalado, ciertamente ha habido avances, pero las leyes que abordan la pornografía infantil en todo el mundo a menudo son débiles o inconsistentes, o no existen (ICMEC, 2016).

En el caso mexicano, la evaluación internacional del marco que regula los delitos cometidos contra menores en México ha sido bien evaluado por los expertos a nivel internacional; sin embargo, aún requiere mejoras y se debe considerar que todo esfuerzo nacional será insuficiente frente a las dimensiones que caracteriza este problema. Es por ello que se considera que, en lo general, la esfera de los delitos informáticos requiere ser atendida por un frente común propuesto en el marco internacional, partiendo con el consenso de lo que son los delitos 


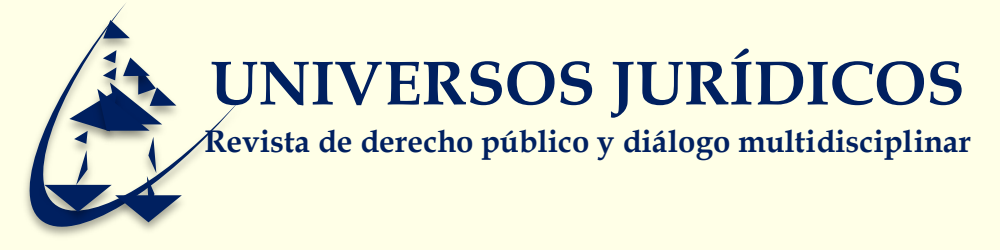

informáticos, con el soporte del equipo técnico especializado, la armonización de las normas y adecuación de los sistemas procesales para investigaciones nacionales.

\section{Fuentes de consulta}

B Catalina García, MC López de Ayala López, A García Jiménez (2014): Los riesgos de los adolescentes en Internet: los menores como actores y víctimas de los peligros de Internet. Revista Latina de Comunicación Social, $69 . \quad$ Recuperado de http://www.revistalatinacs.org/069/paper/1020_UR/23es.html

Cassou Ruíz, Jorge Esteban (2009). Delitos informáticos en México. Instituto de la Judicatura Federal. No. 28. Recuperado de https://www.ijf.cjf.gob.mx/publicaciones/revista/28/Delitos informáticos.pdf

CEPAL (2014). Uso seguro de las TIC puede ayudar a niños y adolescentes a ejercer mejor sus derechos. Octubre. Recuperado de https://www.cepal.org/es/comunicados/uso-seguro-de-las-tic-puede-ayudarninos-y-adolescentes-ejercer-mejor-sus-derechos

Diario Oficial de la Federación (2007). Código Penal Federal. Recuperado de https://www.oas.org/juridico/spanish/cyb mex cod penal.pdf

Duran Padilla, José Arturo (2010). Riesgo y regulación en la red en México. Revista mexicana de ciencias políticas y sociales. Vol. 52, no. 209, México. Mayo-agosto. Recuperado de http://www.scielo.org.mx/scielo.php?script=sci arttext\&pid=S018519182010000200002

García-Piña, Corina Araceli (2008). Riesgos del uso de internet por niños y adolescentes. Estrategias de seguridad. Acta Pediátrica de México, vol. 29, núm. 5, septiembre-octubre. Instituto Nacional de Pediatría. Recuperada en https://www.redalyc.org/pdf/4236/423640313006.pdf.

Instituto Federal de Telecomunicaciones (2020). Encuesta Nacional sobre Disponibilidad y uso de Tecnologías de la Información en los Hogares, 2019. Febrero. Recuperada de https://www.inegi.org.mx/contenidos/saladeprensa/boletines/2020/OtrTemE con/ENDUTIH 2019.pdf 


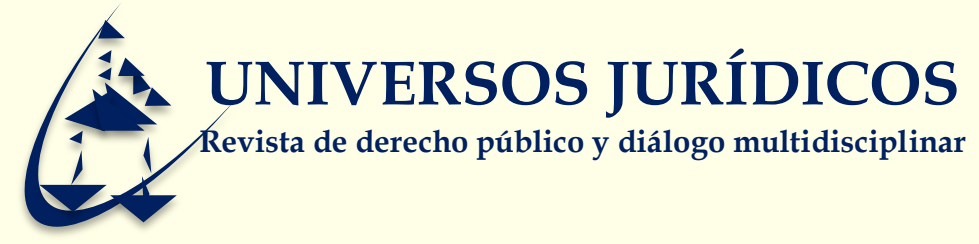

International Centre for Missing \& Exploited Children. Pornografía Infantil: Modelo de legislación y revisión global. 8a edición 2016, p iv. Recuperada en https://www.icmec.org/wp-content/uploads/2016/05/CPML-8th-Ed.-ES.pdf

Jiménez Mesa, José. Riesgos de las redes sociales informáticas. Universidad de Málaga, Julio 2014.2 Recuperada en: https://riuma.uma.es/xmlui/bitstream/handle/10630/15231/Riesgos\%20de\% 20las\%20Redes\%20Sociales\%20Informáticas\%20\%5BCopia\%201\%5D.pdf ?sequence $=1$ \&isAllowed $=\mathrm{y}$

Reyna Alfaro, Luis (2002), Pornografía e Internet: aspectos penales, Revista de Derecho Informático, núm. 050, septiembre. Recuperada en http://www.alfa-redi.org/rdi-artículo.shtml?x=1449.

RTVE (5 de octubre de 2017) Más del 88\% de los niños de 10 años usa equipos de cómputo $y$ accede a internet. Recuperada en http://www.rtve.es/noticias/20171005/mas-del-88-ninos-10-anos-usaordenadores-accede-internet/1626076.shtml

Sánchez-Teruel, D. \& Robles-Bello, M. A. (2016). Riesgos y potencialidades de la era digital para la infancia y la adolescencia. Revista Educación y Humanismo. Volumen (18). Recuperada en http://dx.doi.org/10.17081/eduhum.18.31.1374

UNICEF (2012). Centro de Investigaciones Innocenti. La seguridad de los niños en línea. Retos y estrategias mundiales. Recuperada en https://www.unicefirc.org/publications/pdf/ict_spa.pdf

UNICEF (2017). El Estado Mundial de la Infancia 2017. Niños en un mundo digital.

https://www.unicef.org/peru/sites/unicef.org.peru/files/2019-

01/Estado_Mundial_de_la_Infancia_2017._Ninos_y_ninas_en_un_mundo_ digital._Resumen_Ejecutivo___UNICEF.PDF

III Congreso Mundial sobre contra la Explotación Sexual de Niños, Niñas y Adolescentes, "Declaración de Río de Janeiro y Llamado a la Acción para prevenir y detener la explotación sexual de niños, niñas y adolescentes, (2008). Recuperada en https://www.google.com/url?sa=t\&rct=j\&q=\&esrc=s\&source=web\&cd=\&ved $=$ 2ahUKEwiUsCn76DrAhUNI6wKHcTbCkwQFiAAegQIAxAB\&url=http\%3A \%2F\%2Fwww.ilo.org\%2Fipecinfo\%2Fproduct\%2Fdownload.do\%3Ftype\%3 Ddocument\%26id\%3D13934\&usg=AOvVaw0NQQNc4emJrpNf3WSB7Jh2 
